\title{
Concordance between Triglyceride Glucose Index and Admission Insulin Resistance Index in Non-diabetic Subjects of Acute Coronary Syndrome
}

\author{
Andi Irham ${ }^{1}$, Husaini Umar ${ }^{2 *}$, Fabiola Maureen Shinta Adam² ${ }^{2}$ Idar Mappangara ${ }^{3}$, Syakib Bakri ${ }^{4}$, Risna Halim ${ }^{5}$, Alfian Zainuddin ${ }^{6}$ \\ ${ }^{1}$ Department of Internal Medicine, Faculty of Medicine, Hasanuddin University, Makassar, Indonesia; ${ }^{2}$ Department of Internal \\ Medicine, Division of Endocrine Metabolic and Diabetes, Faculty of Medicine, Hasanuddin University, Makassar, Indonesia; \\ ${ }^{3}$ Department of Internal Medicine, Division of Cardiology and Vascular Medicine, Faculty of Medicine, Hasanuddin University, \\ Makassar, Indonesia; ${ }^{4}$ Department of Internal Medicine, Division of Nephrology and Hypertension, Faculty of Medicine, \\ Hasanuddin University, Makassar, Indonesia; ${ }^{5}$ Department of Internal Medicine, Division of Tropical Medicine and Infectious \\ Disease, Faculty of Medicine, Hasanuddin University, Makassar, Indonesia; ${ }^{6}$ Department of Biostatistics, Faculty of Public \\ Health, Hasanuddin University, Makassar, Indonesia
}

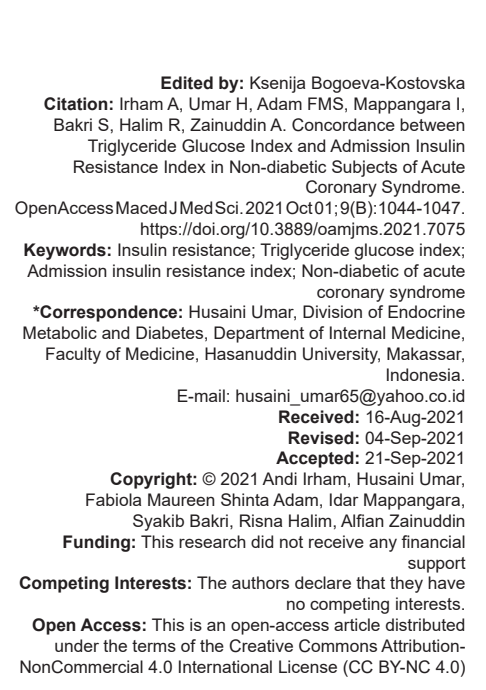

\section{Abstract}

BACKGROUND: Acute coronary syndrome (ACS) is the leading cause of death in the world and is closely related to insulin resistance (IR). The examination of the triglyceride glucose (TyG) Index and admission IR index (AIRI) can be an alternative examination to assess IR.

AIM: The aim of the study was to analyze the concordance between the TyG index and AIRI in assessing IR in nondiabetic subjects of ACS.

METHODS: This study was a cross-sectional study using secondary data from ACS patient medical records in Wahidin Sudirohusodo Hospital Makassar from September 2020 until April 2021. An examination of RBG, TyG, and fasting insulin was performed. The statistical test results were considered significant if the $p<0.05$.

RESULTS: This study included 67 subjects, of which 54 were male and 13 were female, there were 24 people aged $<50$ years, 43 people aged 50 years old, with a mean of $55.15 \pm 12.71$ years, a diagnosis of ST-elevation myocardial infarction (STEMI) 25 people, non STEMI 34 people and unstable angina pectoris 8 people, $\mathrm{p}<0.05$. The receive operating characteristic curve showed that the cut-off value of the TyG index in predicting AIRI was 3141, with a sensitivity of $88.98 \%$ and specificity of $59.09 \%$. The OR value revealed that subjects with a TyG index of $>9.06$ indicated an 11-time greater risk for IR than subjects with a TyG index $\leq 9.06$

CONCLUSIONS: There was a significant concordance between the TyG index and the AIRI in non-diabetic acute coronary syndrome patient.

\section{Introduction}

Cardiovascular disease is the leading cause of death in the world and is often associated with various comorbidities such as obesity, abnormal lipid profile, and insulin resistance (IR) [1], [2]. The most common cardiovascular disease is acute coronary syndrome (ACS). ACS is divided into three groups, namely, ST-elevation myocardial infarction (STEMI), non STEMI (NSTEMI), and unstable angina (UA) [3].

The high population with chronic disease associated with IR has been widely reported worldwide [4]. The mechanism of IR in the heart is complex and multifactorial. Impaired insulin-stimulated glucose absorption is still a common problem, changes in signaling kinases can be increased or decreased, thus impacting cardiac structure and function. IR generally occurs mainly as a result of obesity, excess calories, lack of physical activity, genetics, and age. $\mathrm{IR}$ is associated with many serious medical conditions such as type 2 diabetes mellitus, hypertension, atherosclerosis, and metabolic syndrome (MetS) [5].

Systemic inflammation also contributes to IR, proinflammatory cytokines induce IR which can affect glucose and fatty acid utilization by inducing IR, inflammation increases the heart's dependence on triglycerides from the liver and free fatty acids from adipose tissue for energy [6]. Obesity can increase circulating concentrations of inflammatory cytokines, such as interleukin-6 tumor necrosis factor- $\alpha$ and leptin [2].

Hyperinsulinemia Euglycemic Clamp is still the gold standard to diagnose $I R$, but this method is expensive, invasive, and difficult to perform in health 
facilities [7]. There are various kinds of IR tests, such as quantitative insulin sensitivity check index, fasting glucose to insulin ratio), dan insulin-modified feasibility intravenous glucose tolerance test but each of these methods is not currently available in all health services [8]. Alternative examination that has relatively low cost, fast results and can easily predict $\mathrm{RI}$ is admission IR index (AIRI) and triglyceride glucose (TyG) index [5], [9]. Even though AIRI is expensive than TyG Index, but the subjects does not need to fast.

Luo et al. conducted a study of 1092 patients with STEMI and received percutaneous coronary intervention. This study divided patients into 4 groups according to their level of TyG Index, the patients were then conducted a study for 1 year. The results showed that the higher the TyG Index, the higher the incidence of STEMI [10]. The study of Aman et al. showed the TyG index in predicting HOMA-IR was 4.66 , with the sensitivity of $86.2 \%$ and specificity of $44.1 \%$. The OR value revealed that subjects with TyG index of $\geq 4.66$ indicated a 5-time greater risk for IR than subjects with a TyG index $<4.66$ [11].

This study aims to investigate the concordance between the TyG index and AIRI in assessing IR in nondiabetic subjects of ACS.

\section{Methods}

\section{Research design}

This study was cross-sectional study using secondary data from ACS patient medical records in Wahidin Sudirohusodo Hospital Makassar from September 2020 until April 2021.

\section{Research subject}

Research subjects were taken with consecutive sampling from all patients who entered the emergency room Wahidin Sudirohusodo Hospital Makassar from September 2020 until April 2021 and met the research criteria. Inclusion criteria were ACS subjects aged $>18$ years old, no history of diabetic, and willing to taked part in research. Exclusion criteria were when the subject aged $\leq 18$ years old and refuse to taked part in research.

\section{Research data collection}

Research subjects were non-diabetic subjects of ACS who met the research criteria then we collected their triglyceride levels, RBG levels, insulin levels (without fasting) and used formula to determined TyG index and AIRI subjects.

\section{Data analysis}

Data analysis was performed using SPSS. The statistical test used Anova test if the data is normally distributed or the Kruskal Wallis test if the data is not normally distributed. To find the correlation between AIRI and TyG use the Pearson Correlation test if the data is normally distributed or the Spearmen Correlation test if the data is not normally distributed. The results were considered significant if the $p<0.05$.

\section{Research permit and ethical eligibility}

This research protocol has been approved by the Health Research Ethics Committee, Medical Faculty, Hasanuddin University Makassar, according to the ethical approval recommendation letter number: 165/UN4.6.4.5.31/PP36/2020.

\section{Results}

The study was conducted at the emergency unit installation and the treatment installation at Wahidin Sudirohusodo Hospital and a network hospital from September 2020 to April 2021. This study involved 67 subjects who met the inclusion criteria. Statistical analysis carried out was descriptive statistical calculations and statistical tests of spearman correlation, and receiver operating characteristic (ROC) curve. The results of statistical tests were significant if $p<0.05$.

Data analysis was conducted on 67 subjects of which 54 were male and 13 were female. The incidence of heart disease will increase at the age of 50 years, 39 in this study found 24 people aged $<50$ years, 50 years 43 people, with a mean of $55.15 \pm 12.71$ years, a diagnosis of STEMI 25 people, NSTEMI 34 people and unstable angina pectoris (UAP) 8 people. The characteristics of the research subjects had fasting blood glucose (FBG) 108.04 \pm 20.52 , TG $141.22 \pm 52.67$, AIRI $28.87 \pm 15.98$, and TyG index $8.86 \pm 0.39$ (Table 1).

Table 1: Sample characteristic $(n=67)$

\begin{tabular}{|c|c|c|}
\hline Variables & $\mathrm{n}($ mean.$\pm \mathrm{SD})$ & $\% /$ median (min-max) \\
\hline \multicolumn{3}{|l|}{ Gender } \\
\hline Male & 54 & 80.6 \\
\hline Female & 13 & 9.4 \\
\hline \multicolumn{3}{|l|}{ Age (years) } \\
\hline$<50$ & 24 & 35.8 \\
\hline$\geq 50$ & 43 & 63.2 \\
\hline \multicolumn{3}{|l|}{ Diagnosis } \\
\hline ST elevation myocardial infarction & 25 & 37.3 \\
\hline $\begin{array}{l}\text { Non-ST elevation myocardial } \\
\text { infarction }\end{array}$ & 34 & 50.7 \\
\hline Unstable angina pectoris & 8 & 11.9 \\
\hline Triglyceride & $141.22 \pm 52.67$ & $132(58-330)$ \\
\hline RBG & $134.46 \pm 27.60$ & $129(81-220)$ \\
\hline Fasting blood glucose & $108.04 \pm 20.52$ & $(68-191)$ \\
\hline Admission insulin resistance index & $28.87 \pm 15.98$ & $25.39(8.51-98.76)$ \\
\hline Triglyceride glucose & $8.86 \pm 0.39$ & $8.86(7.80-9.84)$ \\
\hline
\end{tabular}

Figure 1 shows the results of the ROC curve analysis showed the area under curve value was 0.799 


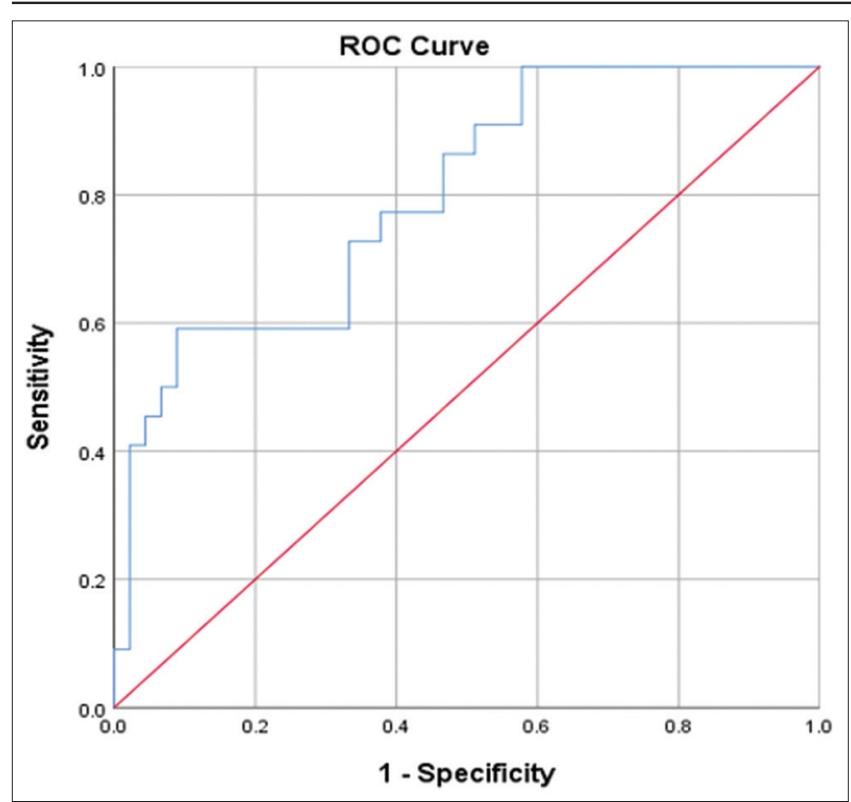

Figure 1: Receiver operating characteristic curve of triglyceride glucose index on homeostasis model assessment of insulin resistance

$(p<0.01)$. This means that the TyG Index is quite sensitive in predicting the AIRI value with a cutoff value of 31.41. Figure 2. illustrates the positive correlation between the TyG index and AIRI ( $p=0.001)$ with a correlation strength of 0.359 is in the category of moderate correlation and the direction is positive (the higher the value of AIRI, the higher the value of TyG or otherwise).

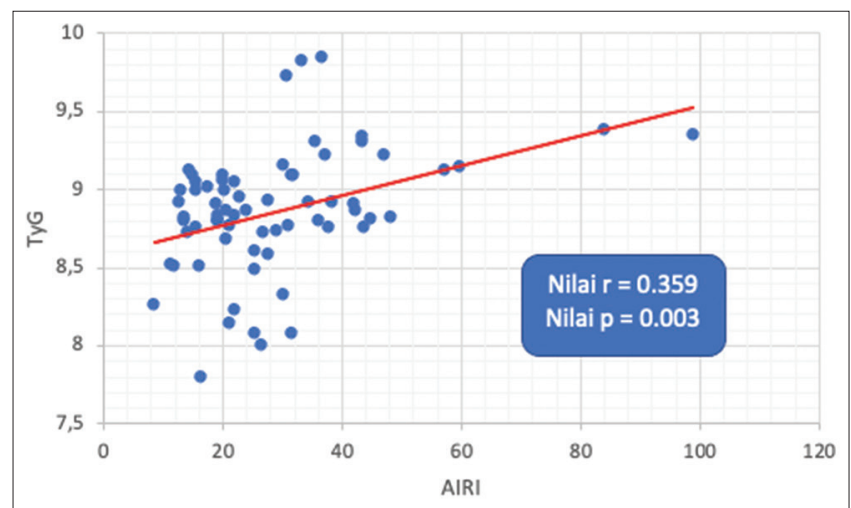

Figure 2: Positive correlation between triglyceride glucose index and admission insulin resistance index

Table 2, shows that there is a positive correlation between TyG and AIRI index with $p<0.001$, sensitivity reached $88.80 \%$ and specificity $59.09 \%$. Based on OR, subjects with TyG index $>9.06$ had an 11.556 times greater risk of experiencing $\mathrm{RI}$ than subjects with TyG index 8062.

Table 2: Triglyceride glucose index with admission insulin resistance index based on receiver operating characteristic curve

\begin{tabular}{llllllll}
\hline $\begin{array}{l}\text { Triglyceride } \\
\text { glucose }\end{array}$ & $\begin{array}{l}\text { Admission insulin } \\
\text { resistance index }\end{array}$ & & $\mathrm{n}$ & $\mathrm{p}$ value & Sensitivity & Specify & OR \\
\cline { 2 - 6 } & $\leq 31.41$ & $>31.41$ & & & & & \\
\hline$\leq 9.06$ & 40 & 9 & 49 & 0.001 & $88.80 \%$ & $59.09 \%$ & 11.556 \\
$>9.06$ & 5 & 13 & 18 & & & & \\
$\mathrm{n}$ & 45 & 22 & 67 & & & & \\
\hline
\end{tabular}

The number of subjects of this study was 67 which 54 were male and 13 were female Non-Diabetic subjects of ACS. The incidence of heart disease will increase at the age of 50 years [12], in this study we found 24 people aged $<50$ years, $\geq 50$ years 43 people, with a mean of $55.15 \pm 12.71$ years, a diagnosis of STEMI 25 people, NSTEMI 34 people and UAP 8 people. The characteristics of the research subjects had FBG $(108.04 \pm 20.52$, TG $141.22 \pm 52.67$, AIRI $28.87 \pm 15.98$, and TyG index $8.86 \pm 0.39$.

In this study, the relationship between AIRI and TyG was found where $(p=0.001)$ with $a$ correlation strength of 0.359 was in the category of moderate correlation and the direction was positive. From the results of this study, the TyG index and AIRI can be used as markers to detect resistance. IR can increase the risk of hyperglycemia, hypertension, and dyslipidemia which increases the risk of inflammation, changes in coagulation factors, atherosclerosis, and coronary heart disease death [13], [14]. The TyG index and AIRI are easy tests to detect the presence of subjects who are at high risk of suffering from cardiovascular disease, high triglyceride levels and fasting glucose are components of MetS which is one of the most important markers of heart disease [15]. A study conducted by Lee et al. concluded that the TyG index was strongly associated with an increased risk of ACS in asymptomatic subjects with type 2 diabetes, especially if they had cardiovascular risk factors [16]. The other study research by Hong et al. which uses the Tyg index as a tool to detect the presence of subjects with high cardiovascular risk [17]. AIRI examination itself conducted by Refaie and Elewa A showed the results that the increase in AIRI can predict coronary artery events in non-diabetic patients with acute chest pain. Multiple coronary vessel involvement is common in such cases and an appropriate planned invasive therapy strategy should be considered [18]. Another study conducted by Abdullah et al. proved an increase in AIRI in patients with ACS [19].

In this study, we divided the AIRI value and the TyG index value based on the tertile. Tertile values 1 and 2 AIRI $\leq 31.41$ tertile $3>31.41$. On the other hand, Rosalina et al. in Makassar concluded that in obese patients, the highest percentage of AIRI tertile $3(70 \%)$ was found compared to AIRI tertile $2(20 \%)$ and AIRI tertile $1(15 \%)$. Meanwhile, those who were not obese were found to have the highest levels of 1 AIRI $(85 \%)$ compared to 2 AIRI (80\%) and 3 AIRI (30\%) [9]. Another study by Refaie and Elewa found that AIRI value significantly increased in acute myocardial infarction $(3.9 \pm 0.1)$ and UAP $(3.01 \pm 0.2)$ when compared with the stable angina and control groups [18].

The average value of the TyG index in this study was $8.86 \pm 0.39$ and the tertile value of TyG index tertile 1 and $2 \leq 9.06$ tertil $3>9.06$. Research conducted by Aman et al. in Makassar got a value of $4.79 \pm 0.25 .40$ [11]. The other research conducted 
by Wang et al. in South Korea divided the Tyg index value into three tertiles, tertile 1 (8.45 \pm 0.29$)$, tertile 2 (9.09 \pm 0.15$)$, and tertile $3(9.94 \pm 0.52)$ [20].

\section{Conclusion}

There was a significant concordance between the TyG index and the AIRI in non-diabetic subjects of ACS patients. TyG index in predicting AIRI was 3141, with a sensitivity of $88.98 \%$ and specificity of $59.09 \%$. The OR value revealed that subjects with a TyG index of $>9.06$ indicated a 11-time greater risk for IR than subjects with a TyG index $\leq 9.06$.

\section{Study limitation}

The limitation of the study was that the blood sample was taken only twice., first at the time of admission to the hospital and when patient was fasting. The sensitivity and specificity of the TyG index that was compared only with AIRI, which is not the gold standard in diagnosing IR.

\section{References}

1. Jan S, Lee SW, Sawhney JP. Catastropic health expenditure on acute coronary events in Asia: A prospective study. Bull World Health Organ. 2016;94(3):193-200. https://doi.org/10.2471/ blt.15.158303

PMid:26966330

2. Ormazabal V, Nair S, Elfeky O, Aguayo C, Salomon C Zuñiga FA. Association between insulin resistance and the development of cardiovascular disease. Cardiovasc Diabetol. 2018;17(1):1- 14. https://doi.org/10.1186/s12933-018-0762-4

3. Juzar DA, Dany SS, Irmalita I, Tobing DPL, Firdaus F, Widyantor B. Pedoman Tatalaksana Sindrom Koroner Akut. Perhimpun Dokter Spesialis Kardiovaskuler Indonesia. Jakarta: Interna Publishing; 2015.

4. Lim J, Kim J, Kwon GC, Koo SH. Comparison of triglyceride glucose index, and related parameters to predict insulin resistance in Korean adults: An analysis of the 2007-2010 Korean National Health and Nutrition Examination Survey. PLoS One. 2019;14(3):e0212963. https://doi.org/10.1371/ journal.pone.0212963

PMid:30845237

5. Abel ED, O'Shea KM, Ramasamy R. Insulin resistance: Metabolic mechanisms and consequences in the heart. Arterioscler Thromb Vasc Biol. 2012;32(9):2068-76. https://doi. org/10.1161/atvbaha.111.241984

PMid:22895668

6. Chen L, Chen R, Wang H, Liang F. Mechanisms linking inflammation to insulin resistance. Int $\mathrm{J}$ Endocrinol. 2015;2015:508409.

PMid:26136779

7. De Souza AL, Batista GA, Alegre SM. Assessment of insulin sensitivity by the hyperinsulinemic euglycemic clamp: Comparison with the spectral analysis of photoplethysmography. J Diabetes Complications. 2017;31(1):128-33. https://doi. org/10.1016/j.jdiacomp.2016.10.018

PMid:27839921

8. Conwell LS, Trost SG, Brown WJ, Batch JA. Indexes of insulin resistance and secretion in obese children and adolescents: A validation study. Diabetes Care. 2004;27(2):314-9. https://doi. org/10.2337/diacare.27.2.314

PMid: 14747206

9. Rosalina R, Umar H, Tandean P, Kasim H, Aman AM, Rasyid H, et al. The comparison of AIRI values in obese and non obese acute coronary syndrome patients. Eurol $\mathrm{J}$ Mol Clin Med. 2020;7(8):190-7.

10. Luo E, Wang D, Yan G, Qiao Y, Liu B, Hou J, et al. High triglyceride-glucose index is associated with poor prognosis in patiens with acute ST-elevation myocardial infarction after percutaneous coronary intervention. J Cardiovasc Diabetol. 2019;18(1):2-12. https://doi.org/10.1186/s12933-019-0957-3 PMid:31722708

11. Aman M, Resnawita D, Rasyid $H$, Kasim H, Bakri S, Umar H, et al. The concordance of triglyceride glucose index (TyG index) and homeostatic model assessment for insulin resistance (Homa-IR) in non-diabetic subjects of adult Indonesian males. Clin Epidemiol Glob Health. 2021;9:227-30. https://doi. org/10.1016/j.cegh.2020.09.003

12. Mozaffarian D, Benjamin JE, Amett KD. Heart Disease an stroke statistics. Circ Aha J. 2015;131(3):1-323.

13. Bonura $F$, Vitale $G$. Insulin resistance and acute coronary syndrome. Atherosclerosis. 2010;211(2):672-5. PMid:20466373

14. Kim MK, Ahn CW, Kang S, Nam JS, Kim KR, Park JS Relationship between the triglyseride glucose index and coronary artery calcification in Korean adults. J Cardiovasc Diabetol. 2017;16(1):1-7. https://doi.org/10.1186/s12933-017-0589-4 PMid:28830471

15. Mao Q, Zhou D, Li Y, Wang Y, Wang Y, Xu SC, Zhao XH. The triglyceride-glucose index predicts coronary artery disease severity and cardiovascular outcomes in patients with nonST-segment elevation acute coronary syndrome. Dis Markers. 2019;2019:6891537. https://doi.org/10.1155/2019/6891537 PMid:31281548

16. Lee EY, Yang HK, Lee J, Kang B, Yang $\mathrm{Y}$, Lee $\mathrm{SH}$, et al Triglyceride glucose index, a marker of insulin resistance, is associated with coronary artery stenosis in asymptomatic subjects with Type 2 diabetes. Lipids Health Dis. 2016;15(1):155. https://doi.org/10.1186/s12944-016-0324-2 PMid:27633375

17. Hong $\mathrm{S}$, Han K, Park CY. The triglyceride glucose index is a simple and low-cost marker associated with atherosclerotic cardiovascular disease: A population-based study. BMC Med. 2020;18(1):1-8. https://doi.org/10.1186/s12916-020-01824-2

18. Refaie W, Elewa A. Admission insulin resistance index in non diabetic patients with acute coronary syndrome; clinical and angiographic features. Egypt Hear J. 2013;65(4):301-5. https:// doi.org/10.1016/j.ehj.2013.02.004

19. Abdullah I, Hasan G, Altunkeser BB, Ozdemir K, Gürbilek M, Gederet $Y \mathrm{~T}$, et al. Evaluation of "admission index of insulin resistance (AIRI)" as an early stage risk predictor in non-diabetic acute coronary syndromes. Anatol J Cardiol. 2002;2(3):194-201. PMid:12223324

20. Wang S, Shi J, Peng Y, Fang Q, Mu Q, Gu W, et al. Stronger association of triglyceride glucose index than the HOMA-IR with arterial stiffness in patients with Type 2 diabetes: A real-world single-centre study. Cardiovasc Diabetol. 2021;20(1):1-10. https://doi.org/10.1186/s12933-021-01274-x 